\title{
Investigation on Effects of Nonlinear Static Procedures on the High Rise Buildings
}

\author{
Sreenath Mahankali ${ }^{1}$ and P.V.V.S.S.R.Krishna ${ }^{2}$ \\ ${ }^{1}$ CVR College of Engineering/ Civil Engineering Department, Hyderabad, India \\ Email: mahankalisreenath.m@gmail.com \\ ${ }^{2}$ CVR College of Engineering/Civil Engineering Department, Hyderabad, India \\ Email: siva.polinas@gmail.com
}

\begin{abstract}
The objective of the paper is to evaluate and compare the structural behavior and response demands by non linear static procedures (NSP's) such as Capacity Spectrum Method recommended in ATC40 and Displacement Coefficient Method recommended in FEMA356. So, for the investigation of the two methods, two of 3-dimensional high rise RC structures with different characteristics are analyzed for investigation. To obtain nonlinear behavior of the buildings under lateral loads, the base force-roof displacement graphs such as capacity curves are determined by pushover analysis. Then four different seismic hazard levels are considered and their corresponding structural responses are determined by using the two evaluations namely CSM and DCM and results are obtained. Comparing structural response quantities (such as maximum displacements) obtained from the NSPs for considered high-rise RC buildings, effects of different evaluations such as DCM and CSM in performance evaluations of the structures are comparatively investigated.
\end{abstract}

Index Terms- Pushover Analysis, Capacity Spectrum Method, Displacement Coefficient Method.

\section{INTRODUCTION}

Past two decades, structural collapses and damages due to severe earthquakes have caused great loss to economy, mostly in large cities. Subsequently, it is important to discuss and examine the present country codes available and also to develop parallel methods which are more realistic in approach to the normal force based design. So for this purpose, displacement is chosen for realistic approach rather than traditional force based methods which is called performance based design (PBD) having displacements (deformations) have been started. In so many nations, like Japan and United States of America various codes are developed like fVision 2000 (SEAOC 1995), FEMA 356 (FEMA 2000), Bluebook [Structural Engineers Association of California (SEAOC) 1999], FEMA 273 (FEMA 1997), and ATC 40 [Applied Technology Council(ATC) 1996] 1. So, the term PBD(Performance Based Design) became more popular in the branch of Structural and earthquake Engineering. And mostly Structural Engineers have to take keen interest in the concepts of PBD in order to design structure resistant to Earthquake attacks. The basic concept of PBD is to perform desirable characteristics even in unfavorable and sudden loadings. And also, it is not possible to verify and check the performance of structure in different states by force based methods. So, to study about the performance of the structure in different states PBD is the best approach. Smaller earthquake attacks have caused an abnormal inelastic behavior in buildings. After recent earthquakes, many buildings have faced to the damages which cannot be repaired or highly economical to repair.

The concepts in PBD, which have multiple stages in design, provide an improvement in the present available codes. So, to determine the response demands for earthquake assessments of structures within Performance Based Design Concept, analysis procedures like non linear static analysis procedures (NSP's) are becoming more popular in Structural Engineering due to its realistic nature. Already some Seismic Codes like Eurocode No. 8 included the non linear static procedures (NSP's) in them. Though nonlinear time history analysis is the most realistic approach in determining the seismic response demands of structures, it need larger input data like (damping ratio, sets of accelerograms etc..,) and provides results which are very difficult to interpret (such as seismic response demands with time and variation of displacement, absorbed energy, etc,.,.). So, to overcome such difficulties, NSPs are mostly used in ordinary engineering applications to avoid large assumptions required by the designer. As a result, simplified NSPs like ATC40, FEMA356, and other became popular.

In NSP's, by pushover analysis for a specified seismic hazard level capacity curves are obtained, from which as we can determine the maximum displacement. From it, other results like plastic rotations, story drifts, displacements, etc, are extracted by using this curve. In FEMA 356 and ATC 40, Single degree of freedom (SDOF) system approach is used in determination of displacement demands in NSPs, which is called as displacement coefficient method (DCM) and capacity spectrum method (CSM), respectively.

The aim of this study is to evaluate and compare structural and nonstructural response demands obtained from CSM recommended in ATC 40 and DCM recommended in FEMA 356, which are most commonly used in practice for performance evaluation. In recent years high-rise buildings are becoming more popular and there are more chances of collapsing due to earthquakes. For these reasons, this investigation performed on the different NSPs is primarily focused on high-rise RC buildings. In this study, two of three-dimensional high-rise RC buildings, including regular and irregular configurations are studied. Then, four different seismic hazard levels such as E1, E2, E3 and E4 are determined by using CSM and DCM. In 
order to determine the performance levels of the buildings, maximum plastic rotation and maximum story drift demands are found for each structure pushed until the related maximum displacement demand is achieved. In the study, maximum displacements in the four hazard levels of two different configurations such as regular and irregular are determined and compared.

\section{A. The Pushover Analysis Method}

In general, to determine the performance of the structure various lateral loads are applied on the building initially starting from zero to the required displacement level and weak points in the structure are found out. Then the performance of the building is determined by studying the status of plastic hinges formed at given target displacement or performance point related to the particular earthquake intensity level. The building is safe and efficient if the demand does not exceed capacity at all hinges. Though the loads applied, earth quake intensities and the evaluation procedures are theoretically correct with respect to the real earthquake events that are occurring; it may differ from the rigorous dynamic analysis in many ways.

\section{B. Evaluation Procedures}

Though the methods for structure evaluation are differ from one another, their basic approach are almost the same and all of them use the bilinear approximation of the pushover curve. This static procedure equates the properties of Multi degree of freedom (MDOF) structures to relevant Single degree of freedom (SDOF) equivalents, and approximates the expected maximum displacement using the Response spectrum of relevant seismic intensity. The different methods in Pushover analysis are ATC 40 (1996) Capacity Spectrum Method (CSM); FEMA 356 (2000) Displacement Coefficient Method (DCM); FEMA 440 (2005) Equivalent Linearization - Modified CSM; FEMA440 [3]- 2005- Displacement ModificationImprovement for DCM

\section{DESIGN SPECIFICATIONS}

For the investigation of Pushover analysis on high rise buildings, two different types of buildings have been modeled in SAP2000. First one is a regular building and the second one is an irregular building and different types of Seismic hazard levels have been considered.

\section{A. Definitions of Seismic hazard levels}

For determining structural responses of the RC buildings four different seismic hazard levels are considered investigated for two different NSPs. These seismic hazard levels are:

1. Low-intensity earthquake (E1);

2. Moderate earthquake (E2);

3. Design earthquake (E3);

4. Maximum earthquake (E4);

As defined in ATC 40 (ATC 1996), FEMA 356 (FEMA

2000), seismic hazard levels indicates nearly the maximum intensity of earthquake which is expected at the relevant earthquake site. In many codes (ATC 40, FEMA 356, TEC, etc.), the maximum, design, and moderate earthquake for a building with building importance factor $(I)$ of 1 , are one with a probability of $2 \%, 10 \%$, and $50 \%$ of occurring within a period of 50 years, respectively. For the lowintensity earthquake, seismic hazard level classifications given in ATC 40(ATC 1996), FEMA 356 (FEMA 2000) are used. Then, the values related to the different earthquake intensity levels are taken from the design spectrum given in the TEC. And with reference to it $\mathrm{E} 1$ is 0.3 times $\mathrm{E} 3 ; \mathrm{E} 2=0.5$ times $\mathrm{E} 3 ; \mathrm{E} 4=1.5$ times $\mathrm{E} 3$.

\section{B. Description of the Building}

The test building is a Ten storey's reinforced concrete building, with each storey having a height of 4.00 $\mathrm{m}$ and bay sized having $8.00 \mathrm{~m}$ along both directions. The columns at the base are rectangular with dimensions $700 \times 650 \mathrm{~mm}$, and same dimensions continued till roof. Column longitudinal reinforcement may be taken between the range of $1.0 \%$ and $2.5 \%$, while $8 \mathrm{~mm}$ diameter bars are used as transverse ties. Beams are designed to dimensions of $750 \times 650 \mathrm{~mm}$ in all storeys and are lightly reinforced (nearly up to $0.4 \%$ steel ratio). The cross-sectional dimensions of columns are relatively narrow, so that the capacity of early designs to be as much as possible low cost in usage of concrete, as it will be in situ mixed and conveyed manually and placed and because of the relatively very low level of seismic action. Hence, in the test structure the columns are slender and not strong enough to carry a large amount of bending caused by lateral forces generated during an seismic attack and subsequently are highly flexible than beams. More details about formwork and reinforcement details can be found in Table. The building has been designed according to IS450:2000,that is the Indian Standard design code, following allowable design stress procedures and simplified structural analysis models. The values of dead and live loads were specified in the Indian Standard Codes, which are still in effect today. Structural elements possess no special reinforcement bars for confinement in the critical section and no capacity design provisions were used in their design. In order to resist negative moments at beams due to gravity loads Longitudinal bars in beams, are bent upwards at their end. However, high intensity earthquake vibrations can alter the moments at the ends of the beams (from sagging to hogging moment). As a result the steel in bottom section of beams at support may not be adequate for earthquake resistance. Moreover, widely spaced stirrups ( 300 to $400 \mathrm{~mm}$ ) do not provide required confinement. Hence, stirrups are unable to withstand large curvature demand due to earthquake loads. For this project two models of high-rise buildings of $\mathrm{G}+10$ are considered. The design specifications of two cases are shown in Table 1 and the 3D view and plan of first case and second case are shown in the Fig. 1, Fig.2, Fig.3 and Fig.4 respectively, 


\section{DESign Specifications OF Structures}

The design specifications of the building 1 and building 2 are shown in table1 TABLE 1

\begin{tabular}{|c|c|c|}
\hline \multicolumn{3}{|c|}{ DESIGN SPECIFICATIONS OF BULLINGS } \\
\hline General Aspects & Design Variable & Selected Criteria For Building \\
\hline \multirow{6}{*}{$\begin{array}{l}\text { General configuration for } \\
\text { design }\end{array}$} & Support Configuration & Fixed \\
\hline & Occupancy and Use & Commercial \\
\hline & Design Standard Code & IS $456: 2000$ \\
\hline & Initial Damping & $5 \%$ \\
\hline & Concrete & M30 \\
\hline & Reinforcement bars & HYSD415 \\
\hline \multirow[t]{8}{*}{$\begin{array}{c}\text { Related geometric } \\
\text { properties }\end{array}$} & Irregularities & $\begin{array}{c}\text { Regular and Symmetric } \\
\text { Building(Building1) \& } \\
\text { Irregular with L-shape and } \\
\text { Symmetric Building(Building2) }\end{array}$ \\
\hline & Basements & Not considered \\
\hline & Number of Stories & 11 \\
\hline & Inter-Story Height & $4 \mathrm{~m}$ \\
\hline & Distribution of bays & Uniform \\
\hline & Typical bay length & $8 \mathrm{~m}$ in both direction \\
\hline & Beam Dimensions & $750 * 600 \mathrm{~mm}$ \\
\hline & Column Dimensions & $700 * 600 \mathrm{~mm}$ \\
\hline \multirow[t]{2}{*}{ Load Configurations } & Additional Dead Load & $2 \mathrm{KN} / \mathrm{m}$ \\
\hline & Live Load & $3 \mathrm{KN} / \mathrm{m}$ \\
\hline \multirow{5}{*}{$\begin{array}{l}\text { Basic considerations for } \\
\text { Nonlinear analysis }\end{array}$} & Configuration model & 3D model \\
\hline & Seismic Hazard Levels & $\begin{array}{l}\text { Low, moderate, Design and } \\
\text { maximum }\end{array}$ \\
\hline & $\begin{array}{l}\text { Plastic moment hinges } \\
\text { consideration }\end{array}$ & Both Beams and columns \\
\hline & $\begin{array}{l}\text { Plastic moment hinges } \\
\text { location }\end{array}$ & $\begin{array}{l}\text { At } 5 \% \text { of span length from each } \\
\text { node }\end{array}$ \\
\hline & Software & SAP2000 \\
\hline
\end{tabular}

The 3D view and plan of the building case 1 and building case 2 are shown in Fig.1 and Fig.2 and Fig.3, Fig.4.
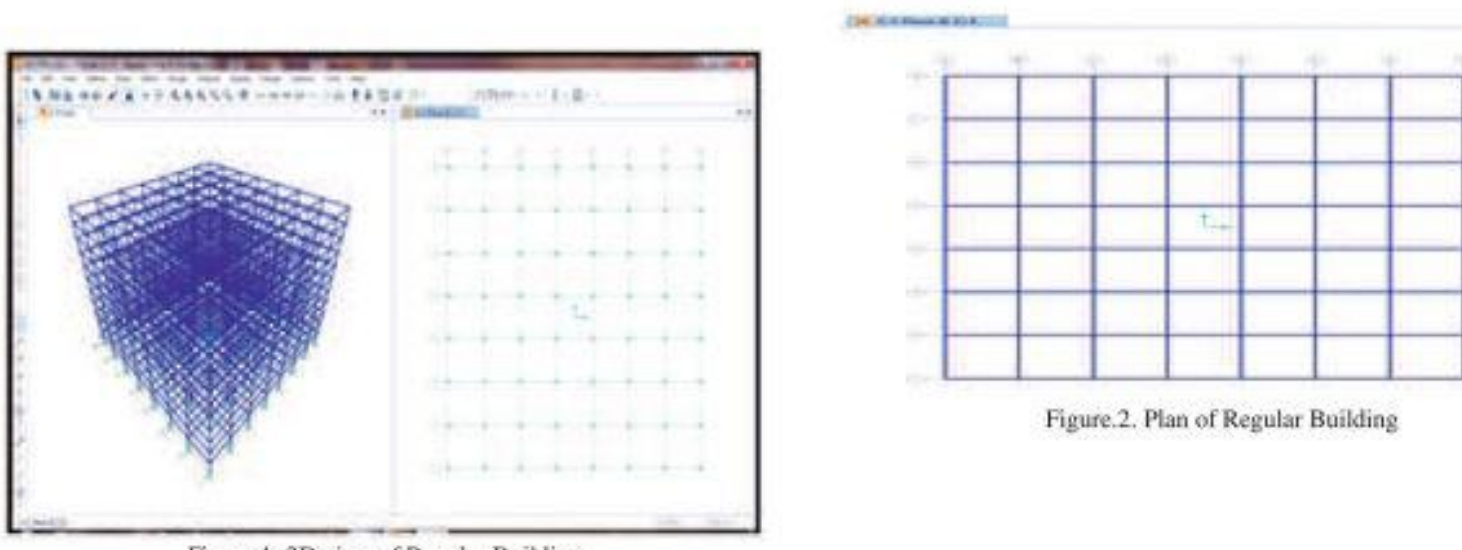

Figure.2. Plan of Regular Building

Figure 1. 3D view of Regular Building 


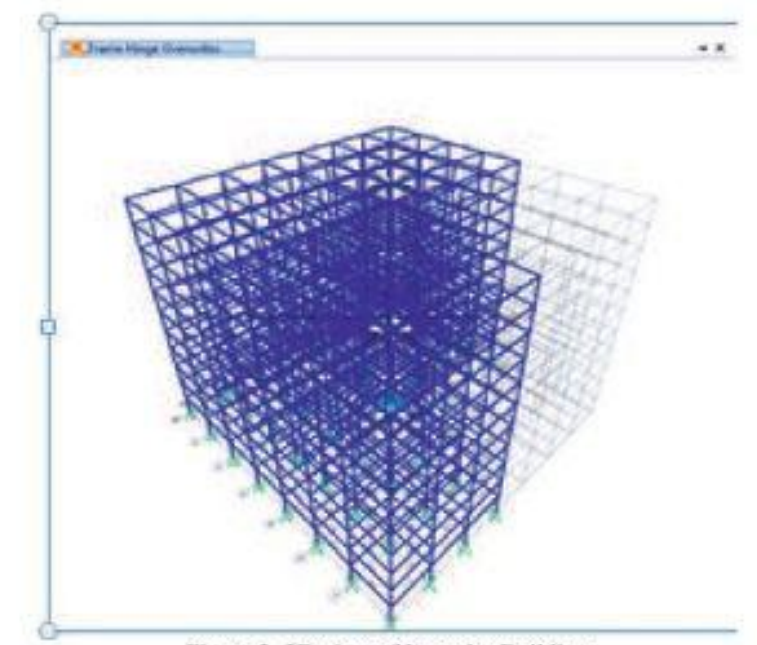

Figure 3. 3D view of Irregular Building

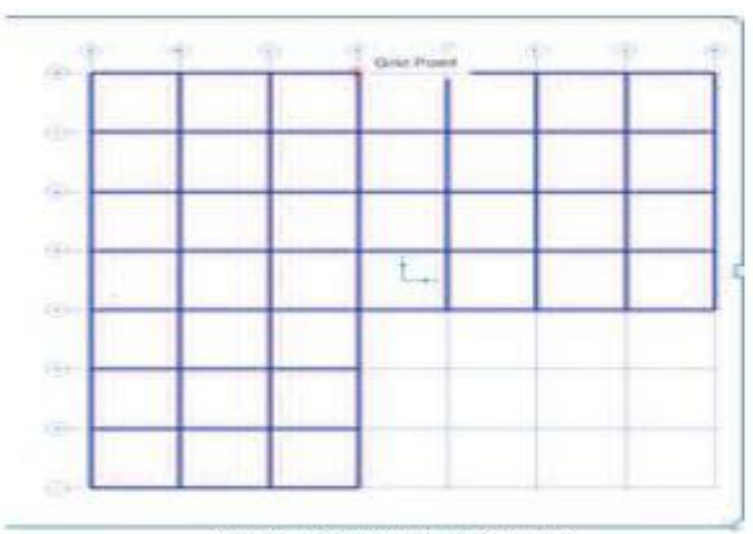

Figure.4. Plan of Irregular Building

\section{RESULTS}

The two cases for different hazard levels are analyzed by using SAP2000. The formation of plastic hinges is shown in the Fig.5. The graph related to CSM of irregular building is shown in Fig.6 and the DCM results of irregular building are shown in Fig. 7.

Table 2: Comparing the Difference in CSM and DCM for four Seismic

\begin{tabular}{|c|c|c|c|}
\hline $\begin{array}{c}\text { Buildi } \\
\text { ng }\end{array}$ & $\begin{array}{c}\text { Seismi } \\
\text { c } \\
\text { Hazar } \\
\text { d } \\
\text { Level }\end{array}$ & $\begin{array}{c}\text { Difference } \\
\text { between } \\
\text { CSM\&DC } \\
\text { M }\end{array}$ & $\begin{array}{c}\text { \%of } \\
\text { difference in } \\
\text { Maximum } \\
\text { Displacement }\end{array}$ \\
\hline \multirow{2}{*}{$\begin{array}{c}\text { Buildi } \\
\text { ng1 }\end{array}$} & E1 & 0.030426 & $5.89 \%$ \\
\cline { 2 - 4 } & E2 & 0.188204 & $36.62 \%$ \\
\cline { 2 - 4 } & E3 & 0.13827 & $26.90 \%$ \\
\cline { 2 - 4 } & E4 & 0.202729 & $39.336 \%$ \\
\hline \multirow{2}{*}{$\begin{array}{c}\text { Buildi } \\
\text { ng2 }\end{array}$} & E1 & 0.064137 & $14.4638 \%$ \\
\cline { 2 - 4 } & E2 & 0.058631 & $14.494 \%$ \\
\cline { 2 - 4 } & E3 & 0.052299 & $12.22 \%$ \\
\cline { 2 - 4 } & E4 & 0.05467 & $14.529 \%$ \\
\hline
\end{tabular}
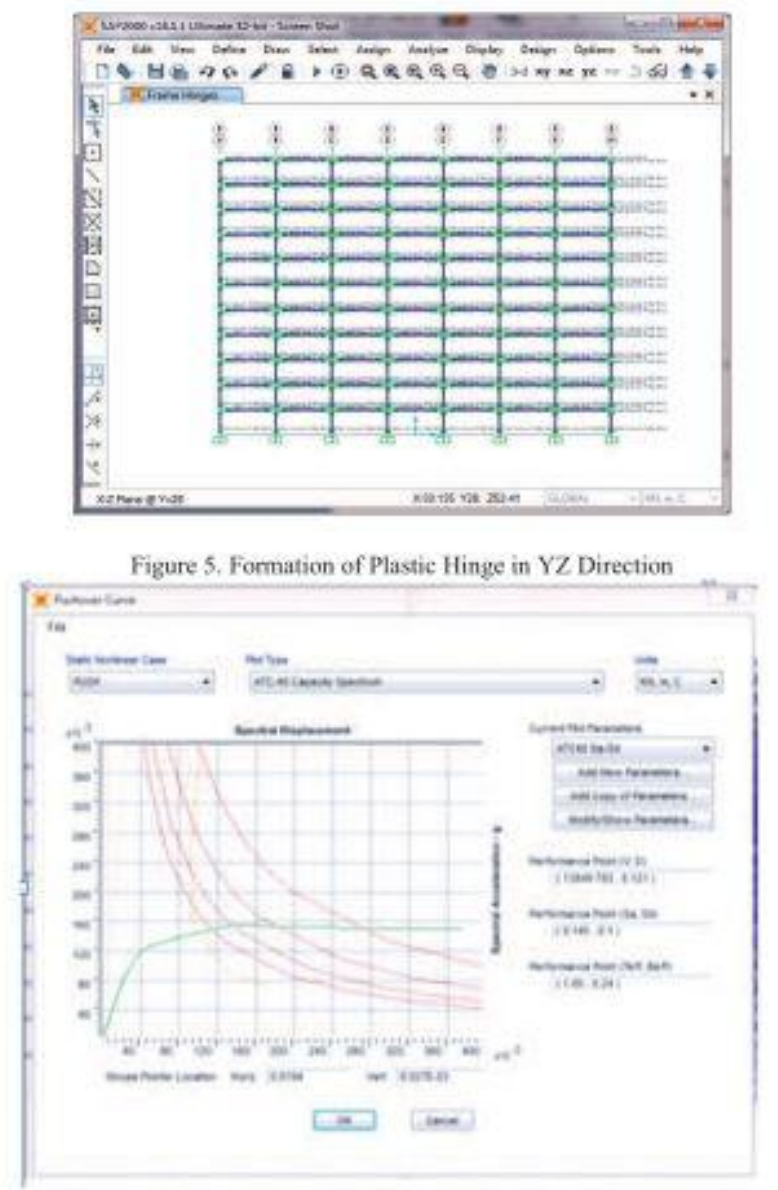

Figure 6. CSM Result of lrregular Building (E3)

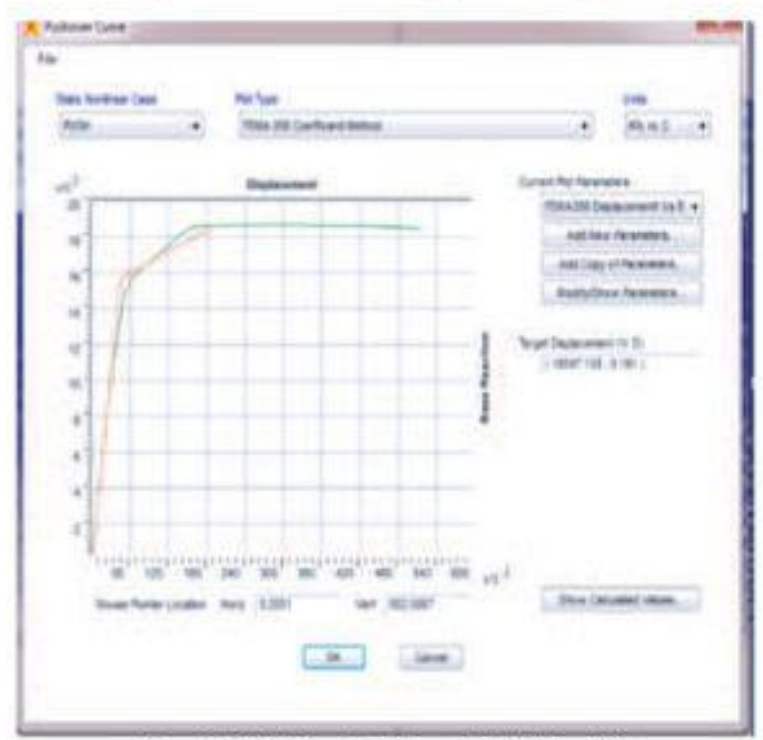

Figure 7. DCM Result of Irregular Building (E3) 


\section{Conclusions}

This paper presented the comparison between the two methods of NSP's by using SAP2000. SAP2000 is one of the best softwares for analyzing the structures as it has a very high accuracy. It is the best tool for exploring and comparing different methods of approach in analyzing. The pushover analysis is one of the important approaches for analyzing the behavior of structure towards seismic attacks. The effect level of the earthquake hazard levels can be easily studied in the form of deformations of the structures. Non-linear pushover analysis serves the basis for determining the capacity of the RC building in terms of base shear and roof displacement when displacement based approach is adopted.

Displacement based approach tends to give realistic opinion of demand over the building as it uses roof displacement as preliminary input parameter. In future times these types of approaches become more popular as the high rise buildings are increasing more in number. Capacity curves of the structures have been plotted. The graph is linear to some extent of base shear and then it becomes constant, this is due to the formation of plastic hinges in the structure. Capacity Spectrum Method is one of the good approaches for Non linear Static Procedures as this approach gives the results about displacements, spectral acceleration $(\mathrm{Sg})$ and Time Periods ( $\mathrm{T}$ ).

The Maximum Displacements for frames by Displacement Coefficient Method recommended by FEMA356 are higher than that of Capacity Spectrum Method recommended by ATC40.For Regular Building (Building Case1) the Percentage Difference in Maximum Displacement between DCM and CSM is gradually increasing from Low Hazard Level to Maximum Hazard Level (E1 to E4). So it concludes that in case of Regular buildings for low seismic hazard levels both the methods will give almost same results where as for high seismic hazard levels, the difference between two methods differ in a great manner. For irregular building (Building Case2) the Percentage Difference in the Maximum Displacement between DCM and CSM is constant for all Hazard Levels (E1 to E4). It concludes that even though the both approaches are different they arise at same results in case of Irregular Buildings.

Though the values are high for the DCM method, it is one of the good approaches for Seismic Evaluation of RC Frames

\section{REFERENCES}

[1] Erdal Irtem and Umut Hasgul(2009): "Investigation of Effects of Nonlinear Static Analysis Procedures to Performance Evaluation on Low-Rise RC Buildings"

[2] Cinitha.A, Umesha, Nagesh R. Iyer(2012); "Nonlinear Static Analysis to Assess Seismic Performance and Vulnerability of Code - Conforming RC Buildings"

[3] Ajay, Shilpa, Babunarayan (2012): " Sensitivity of pushover analysis to design parameters-an analytical investigation"

[4] V.Vysakh Dr. Bindhu K.R. Rahul Leslie(2013): "Determination of Performance Point In Capacity Spectrum Method"

[5] N.K. Manjula, Praveen Nagarajan, T.M. Madhavan Pillai(2013) "A Comparison of Basic Pushover Methods"

[6] Rajesh P Dhakal(2010): "Structural Design For Earthquake Resistance: Past, Present And Future"

[7] L. E. Yamin, Hurtado, J. R. Rincón, J. F. Pulido, J. C. Reyes and A. H. Barbat(2014): " Evaluation of Seismic Code Specifications Using Static Nonlinear Analyses Of Archetype Buildings"

[8] Dominik H. Lang, Dr.-Ing. Dr.philos(2007): "Seismic response estimation using non-linear static methods"

[9] Jorge Ruiz-García , Erick J. González(2013): "Implementation of Displacement Coefficient method for seismic assessment of buildings built on soft soil sites"

[10] Ioannis Giannopoulos(2009): "Seismic Assessment of a RC Building according to FEMA 356 and Eurocode 8"

[11] Bruce F. Maisonl And Carl F. Neuss(2015): "Dynamic Analysis Of A Forty-Four Story Building"

[12]Cinitha.A, P.K. Umesha , Nagesh R. Iyer(2010): "Seismic Performance And Vulnerability Analysis of Code-Conforming Rc Buildings"

[13] Sinan Akkar And Asli Metin(2007): "Assessment Of Improved Nonlinear Static Procedures In Fema-440"

[14]Mohammad Azaz(2015): "Pushover Analysis On G+10 Reinforced Concrete Structure For Zone Ii And Zone Iii Ad Per ls 1893 (2002)"

[15]Dr. Mayank Desai and Darshit Jasani(2015): "Application Of Nonlinear Static Pushover Procedure To The Displacement Based Approach Of Seismic Analysis of $G+10$ Storey Building Structure For Indian Terrain"

[16] M.Mouzzoun, Moustachi, A.Taleb, S.Jalal (2013): "Seismic Performance Assessment Of Reinforced Concrete Buildings Using Pushover Analysis" 